\title{
Shear Bond Strength of Ormocer-Based Restorative Material Using Specific and Nonspecific Adhesive Systems
}

\author{
Ibrahim M. Hamouda and Salah H. Shehata \\ Faculty of Dentistry, Mansoura University, Mansoura 35516, Egypt \\ Correspondence should be addressed to Ibrahim M. Hamouda, imh100@hotmail.com
}

Received 14 April 2011; Accepted 7 June 2011

Academic Editors: S. J. Milne and A. Neto

Copyright ( $) 2011$ I. M. Hamouda and S. H. Shehata. This is an open access article distributed under the Creative Commons Attribution License, which permits unrestricted use, distribution, and reproduction in any medium, provided the original work is properly cited.

\begin{abstract}
The aim of this study was to evaluate the shear bond strength of ormocer-based restorative material bonded to tooth structure using specific ormocer and nonspecific resin-based adhesives. Human molars were prepared to obtain flat buccal enamel surfaces and flat occlusal dentin surfaces. Admira bond, and Prime \& Bond NT, Excite, AdheSE, and Prompt-L-Pop were applied to the prepared enamel and dentin surfaces. Ormocer restorative material was inserted into a mold fixed onto the prepared tooth surfaces. The restorative material was applied and cured. The shear bond strength was measured using a universal testing machine. The highest bond strength was recorded for Admira bond. The non-specific adhesives (AdheSE and Prompt-L-Pop) were recorded the lowest bond strength. Etch \& Rinse (Prime \& Bond NT and Excite) adhesives were recorded an intermediate values. Admira bond usually showed cohesive failure in the material with enamel and cohesive and mixed failure with the dentin. Etch \& Rinse adhesives showed mixed failure with the enamel and, mixed and adhesive failures with the dentin. Self-etching adhesives commonly exhibited adhesive mode of failure. So, Etch \& Rinse, non-specific bonding agents can be used with Admira ormocer-based restorative material when the specific adhesive is depleted.
\end{abstract}

\section{Introduction}

Today, improvements in formulations, optimization of properties, and the development of new techniques for placement have made the restoration of direct composite more reliable and predictable [1]. The resin matrix has an important influence on the properties of the composite resins besides the filler system [2]. There are a great number of resin composites based on conventional monomer systems such as Bis-GMA, UDMA, TEGDMA, and Bis-EMA. The most recent innovation in the monomer system has been the ormocer (organically modified ceramic) technology and filler particles [3].

Ormocer is the acronym for organically modified ceramics. This class of material represents a novel inorganicorganic copolymer in the formulation that allows for modification of the mechanical parameters. The inorganicorganic copolymers are synthesized from multifunctional urethane and thioethermethacrylate alkoxysilanes as $\mathrm{Si}-\mathrm{O}-\mathrm{Si}$ network by hydrolysis and polycondensation reactions. The methacrylate groups are available for photochemical polymerization. The filler particles $\left(\mathrm{ZrO}_{2}\right.$ or $\left.\mathrm{SiO}_{2}\right)$ are $1-1.5 \mu \mathrm{m}$ in size and $77 \%$ by weight loading $[4,5]$. Conventional adhesive systems work in three steps: etching, priming, and bonding. Recently, in an effort to simplify bonding procedures, two-steps and one-step adhesives were developed [6]. The advance in adhesive systems has made it necessary to evaluate their effectiveness in bonding restorative materials to enamel and dentin substrate. Some in vitro methods have been extensively used to do this, including the shear, tensile, and microtensile bond strength tests. Shear test have been reported as the most prevalence in the literature $[7,8]$.

This study was designed to evaluate and compare the shear bond strength and mode of failure of ormocer-based restorative material to both enamel and dentin substrates using the specific ormocer-based adhesive and nonspecific adhesive systems. The nonspecific adhesive systems include 
two types of the Etch \& Rinse and two of the self-etching adhesives.

\section{Materials and Methods}

Seventy, noncarious, extracted human permanent molars were used. The teeth were stored in $0.1 \%$ thymol solution after extraction. The teeth were cleaned from the remaining soft tissues and then stored in distilled water until use. The teeth were divided into two groups, 35 teeth each. Thirtyfive molars were prepared at the buccal surfaces to obtain flat enamel surfaces of at least $5 \mathrm{~mm}$ in diameter. The buccal surfaces were ground flat with orthodontic model trimmer (FARO, Italy). The roots of the teeth were removed with a diamond disc (Edenta, Euadd, Edenia, GmbH, Switzerland). The teeth were embedded in $3 / 4$ inch polyvinyl chloride rings with self-cured acrylic resin (IMI cryl, Turky). The enamel surfaces were ground flush with the acrylic resin by using silicone carbide paper 600 grit (Resista, OMEGNA Nia Filli DiDa/Italy) on a polishing machine. Finally, the enamel surfaces were cleaned with distilled water and dried with oil-free air. Thirty-five molars were prepared at the occlusal surfaces to obtain flat dentin surfaces. The trimming was extended $1.5 \mathrm{~mm}$ apical to the deepest occlusal pit. The teeth were mounted and ground flush with the self-cured acrylic resin. Finally, the dentin surfaces were cleaned and dried.

The prepared teeth were classified into 5 groups for either enamel or dentin, 7 teeth each. The bonding agents were applied to the prepared teeth surfaces as follows: Admira Bond (Voco GmbH, Cuxhaven, Germany), Prime \& Bond NT (Dentsply Detrey Kontanz, Germany), Excite and AdheSE (Ivoclar/Vivadent, Liechtenstein), and PromptL-Pop (3M ESPE, Dental Product, St Paul MN, USA) were applied according to the manufacturer's instructions. The first three adhesive systems required total etching with 37\% phosphoric acid gel (Total Etch, Ivoclar Vivadent, Liechtenstein). The acid gel was applied for enamel surfaces for 30 seconds and the dentin for 15 seconds. The gel was washed for 25 seconds with water and dried with oil-free air for 15 seconds. In such a way, the enamel surface showed typical chalk-like appearance and the dentin surface was still moist. Single coat of each adhesive was applied to both enamel and dentin surfaces with disposable brush and left undisturbed for 15 seconds. The solvent was removed by blowing gently with air for 5 seconds and then light polymerized for 20 seconds using Astralize 3 (Ivoclar Vivadent, Liechtenstein) halogen light-curing unite. The fourth adhesive (AdheSE) is a two-step self-etching adhesive; it was applied to the enamel and dentin surfaces. Adequate amount of AdheSE primer was applied to the substrate and brushed for 15 seconds, then the AdheSE bond was applied and dispersed with a very weak stream of air and light-cured for 10 seconds. The fifth adhesive (Prompt-L-Pop) is one-step self-etching adhesive; it is applied to the enamel and dentin surfaces. Adequate amount of the adhesive was applied and left undisturbed for 20 seconds and then dispersed with a very weak stream of air and light-cured for 20 seconds.

The restorative material was applied as follow: teflon ring mold of $4 \mathrm{~mm}$ diameter and $4 \mathrm{~mm}$ height was placed
TABLE 1: Mean shear bond strength (Mpa) of Admira restorative material to enamel substrate using the various adhesive systems.

\begin{tabular}{lcccc}
\hline Adhesive system & Mean & SD & $P$ value & $F$ value \\
\hline Admira bond & $23.43^{\mathrm{A}}$ & 3.2 & 0.0001 & 36.15 \\
Prime \& Bond NT & $22.78^{\mathrm{A}}$ & 3.39 & & \\
Excite & $19.66^{\mathrm{B}}$ & 3.26 & & \\
AdheSE & $14.24^{\mathrm{C}}$ & 2.8 & & \\
Prompt-L-Pop & $12.04^{\mathrm{D}}$ & 2.13 & & \\
\hline
\end{tabular}

Means with the same superscripts are not significantly different.

and fixed against the prepared surfaces (enamel or dentin). Ormocer-based restorative material (Admira, Voco GmbH, Cuxhaven, Germany) was inserted into the mold in 2 increments of $2 \mathrm{~mm}$ each; each increment was cured for 40 seconds. The samples were stored in distilled water at $37^{\circ} \mathrm{C}$ for 24 hours before testing.

2.1. Bond Strength Measurement. The samples were mounted in the universal testing machine (Lloyd instrument LTD, West Fareham, England) using specially designed grips. The upper part of the testing machine has a knife-edge part to apply the force at the interface of bonding, and the fracture load was recorded in Newtons. shear bond strength was calculated by dividing the load by the cross-sectional area of the bonded restorative material.

2.2. Mode of Bond Failure. The bonded areas were examined with a binocular stereomicroscope $\times 16$ ( Leica, Heerbrugg, AGCH-9435, Switzerland) and then classified into adhesive, cohesive, or mixed mode of failure. Adhesive mode of failure was recorded if the restorative material was completely detached from the tooth structure, cohesive failure if the bond failure was entirely within the restorative material, and mixed failure if the bond failure was a combination of the adhesive and cohesive modes of failure.

2.3. Statistical Analysis. Data were analyzed with one-way analysis of variance (ANOVA) and least significant difference (LSD) test. $t$-test was done to compare the results of the same adhesive system with both enamel and dentin substrates.

\section{Results}

The mean shear bond strength of Admira restorative material to enamel substrate using the various adhesive systems is presented in Table 1. One-way ANOVA test showed significant difference in enamel bond strength among the tested adhesives at 95\% confidence level, $P<0.001$ (Table 1). LSD test showed no significant difference between Admira bond and Prime \& Bond NT adhesives. On the other hand, there was significant difference between Admira bond and Excite, and AdheSE and Prompt-L-Pop adhesives as will as between Excite and AdheSE and Prompt-L-Pop adhesive systems (Table 1).

The mean shear bond strength of Admira restorative material to dentin substrate using the various adhesive 
TABle 2: Mean shear bond strength (Mpa) of Admira restorative material to dentin substrate using the various adhesive systems.

\begin{tabular}{lcccc}
\hline Adhesive system & Mean & SD & $P$ value & $F$ value \\
\hline Admira bond & $21.79^{\mathrm{A}}$ & 2.62 & 0.0001 & 12.159 \\
Prime \& Bond NT & $19.16^{\mathrm{B}}$ & 2.58 & & \\
Excite & $17.66^{\mathrm{B}}$ & 2.33 & & \\
AdheSE & $16.07^{\mathrm{C}}$ & 2.51 & & \\
Prompt-L-Pop & $15.05^{\mathrm{C}}$ & 2.13 & & \\
\hline
\end{tabular}

Means with the same superscripts are not significantly different.

TABLE 3: Mode of failure (number of samples) of the restorative material after debonding from enamel substrate.

\begin{tabular}{|c|c|c|c|}
\hline \multirow{2}{*}{ Adhesive system } & \multicolumn{3}{|c|}{ Mode of failure } \\
\hline & Adhesive & Mixed & Cohesive \\
\hline Admira bond & 1 & 1 & 5 \\
\hline Prime \& Bond NT & 1 & 3 & 3 \\
\hline Excite & 3 & 4 & 0 \\
\hline AdheSE & 6 & 1 & 0 \\
\hline Prompt-L-Pop & 7 & 0 & 0 \\
\hline
\end{tabular}

TABLE 4: Mode of failure (number of samples) of the restorative material after debonding from dentin substrate.

\begin{tabular}{lccc}
\hline Adhesive system & Adhesive & $\begin{array}{c}\text { Mode of failure } \\
\text { Mixed }\end{array}$ & Cohesive \\
\hline Admira bond & 1 & 3 & 3 \\
Prime \& Bond NT & 2 & 3 & 2 \\
Excite & 4 & 3 & 0 \\
AdheSE & 6 & 1 & 0 \\
Prompt-L-Pop & 6 & 1 & 0 \\
\hline
\end{tabular}

systems is presented in Table 2. One-way ANOVA test showed significant difference in dentin bond strength among the tested adhesives at 95\% confidence level, $P<0.001$ (Table 2). LSD test showed significant difference between Admira bond and the other adhesive systems. Also, there was significant difference between Excite and AdheSE and Prompt-L-Pop adhesives as well as between Prime \& Bond NT and AdheSE and Prompt-L-Pop adhesive systems. There was no significant difference in dentin bond strength between Prime \& Bond NT and Excite or between AdheSE and Prompt-LPop adhesive systems (Table 2).

By comparing the mean shear bond strength of enamel to that of dentin, $t$-test revealed that: (1) there was no significant difference for Admira bond adhesive system $(P>$ $0.05),(2)$ there was significant difference for Prime \& Bond NT adhesive system $(P<0.05)$, (3) there was significant difference for Excite adhesive system $(P<0.05)$, and $(4)$ there were no significant differences for both AdheSE and PromptL-Pop adhesive systems $(P>0.05)$. The fracture patterns of the samples to enamel and dentin substrates are presented in Tables 3 and 4, respectively.

\section{Discussion}

Admira is a light polymerizing, ormocer-based restorative material. It contains three-dimensional polymerizable inorganic-organic polymer chains and aliphatic and aromatic dimethacrylate. The resin matrix of Admira consists of ormocer, Bis-GMA, UDMA, and TEGDMA. It contains 78\% inorganic filler, glass ceramic, and $\mathrm{SiO} 2$ particles of $0.7 \mu \mathrm{m}$, and it polymerizes under halogen light [9]. In this study, the Admira bond is compared with the other fifth and six generation materials to demonstrate if these adhesive systems can be used as alternative adhesives to the Admira bond when depleted.

The results of this study showed that the Admira bond had the highest bond strength for both enamel and dentin followed by the Prime \& Bond NT with no significant difference between the two adhesives when they were applied to enamel and with significant difference when they were applied to dentin. Prime \& Bond NT is related to the Etch \& rinse system and has nanofilled, fluoride-releasing character. The nanofiller may improve the adhesive strength to both enamel and dentin and sufficient film thickness from one-coat, one-cure technique. The nanofiller particles are less than one hundredth of the average diameter of dentinal tubules at enamel-dentin junction $(0.8 \mu \mathrm{m})$, and therefore they are fully capable of entering the tubules and the demineralized zone of the dentin. The nanofiller serves as an additional cross-link and therefore strengthens the adhesive layer $[10,11]$. It was concluded that nanoparticle hydroxyapatite particles, produced by hydrothermal routes, were used to infiltrate sections of human dentine. The effect of the particles in blocking the channels in dentine in order to prevent fluid motion was shown. In the long term, this approach may offer an effective means of treating sensitive teeth [12]. Particles prepared at pH 12 had a mean length of approximately $70 \mathrm{~nm}$ and diameter of approximately $30 \mathrm{~nm}$. These showed the most promising infiltration results, with up to $90 \%$ of the tubules being fully or partially occluded [13]. In the present study, these properties explain the recorded cohesive mode of failure of the Admira bond. The viability of the SEM technique for the 3D characterization of dentine tubule structure was considered. It has shown the capability to capture the complex structure and interconnection in a porous insulating biological tissue with nanoscale resolution, but over volumes covering thousands of cubic micrometres [14].

The lowest shear bond strength was recorded for PromptL-Pop with both of enamel and dentin. Prompt-L-Pop is related to the self-etching, one-step adhesive system. This result may be attributed to the effectiveness of self-etching primer systems on properly etching the enamel which also reflected on the adhesive mode of failure of this type of adhesive. Etching of enamel by self-etching primer is less predictable than that of phosphoric acid etching. Removal of smear layer by a separate etching step before bonding would produce a more reliable and durable bond to dentin [15]. Excite and AdheSE exhibited an intermediate shear bond strength with significant difference from the Admira bond and Prime \& Bond NT adhesives. 
Admira bond is a specific formulated primer/adhesive ormocer-based, light-curing system for enamel and dentin bonding. It was reported that Admira bond contains special adhesive ormocer with calcium complexing functionality which enhances the bond strength on tooth structure. Because of the chemical affinity, Admira bond adheres firmly to both the tooth structure and the restorative material. This explains the cohesive mode of failure of the Admira adhesive system [9]. Ormocer-based composite should be used with the matching specially formulated primer/adhesive system, and the practitioner is cautioned not to indiscriminately exchange specific dentin bonding agents for nonspecific ones. This conclusion is somewhat in conflict with the results of our study which indicated that ormocer could be used with nonspecific primer/adhesive system, this may be attributed to the difference in the adhesives used. The researchers in that study used nonspecific self-etching adhesive in addition to specific primer/adhesive for studying microleakage not the bond strength [16].

The bond strength of Prime \& Bond NT and that of Excite adhesive to enamel was significantly different. This result may be attributed to the chemical composition of the adhesives. Although both types of adhesives are nanofilled and alcohol based, Prime \& Bond NT is acetone based while Excite is ethanol-based adhesive but Prime \& Bond NT contains two different types of resins, T-Resin (small, cross-linked molecule) and D-Resin (small, mobile resin molecule). These types of resins enhance resin infiltration compared to Excite adhesive; this explains the significant difference between the bond strength obtained with Prime \& Bond NT and Excite adhesives to enamel. Adhesives that use acetone as the solvent may require a moist dentin substrate to produce adequate bonding [17]. Also, these factors control the behavior of these adhesive during debonding.

\section{Conclusions}

Within limitations of this in vitro study, the following conclusions can be drawn:

(1) ormocer-based restorative material must be used with matching specifically formulated adhesive system and can be used with nonspecific primer/adhesive system with Etch \& Rinse technique specially with Prime \& Bond NT adhesive;

(2) self-etch adhesives were not suitable for use with ormocer-based restorative material

\section{Clinical Relevance}

Prime \& Bond NT adhesive can be used as an alternative to Admira bond when it is depleted.

\section{References}

[1] S. C. Bayne, H. O. Heymann, and E. J. Swift Jr., "Update on dental composite restorations," The Journal of the American Dental Association, vol. 125, no. 6, pp. 687-701, 1994.
[2] M. Kawaguchi, T. Fukushima, and T. Horibe, "Effect of monomer structure on the mechanical properties of lightcured composite resins," Dental Materials Journal, vol. 8, no. 1, pp. 40-45, 1989.

[3] G. C. Leonardo, C. B. A. Roberta, H. S. Paulo, and A. C. Mario, "Comparative study of the surface roughness of ormocerbased and conventional composites," Journal of Applied Oral Science, vol. 11, pp. 1-11, 2003.

[4] J. Manhart, K.-H. Kunzelmann, H. Y. Chen, and R. Hickel, "Mechanical properties and wear behavior of light-cured packable composite resins," Dental Materials, vol. 16, no. 1, pp. 33-40, 2000.

[5] A. M. Kielbassa, U. Muller, and F. Garcia-Godoy, "In situ study on the caries-preventive effects of fluoride releasing materials," American Journal of Dentistry, vol. 12, pp. S13-S14, 1999.

[6] B. Van Meerbeek, J. Perdigao, P. Lambrechts, and G. Vanherle, "The clinical performance of adhesives," Journal of Dentistry, vol. 26, no. 1, pp. 1-20, 1998.

[7] D. H. Pashley, H. Sano, B. Ciucchi, M. Yoshiyama, and R. M. Carvalho, "Adhesion testing of dentin bonding agents: a review," Dental Materials, vol. 11, no. 2, pp. 117-125, 1995.

[8] S. K. Al-Salehi and F. J. T. Burke, "Methods used in dentin bonding tests: an analysis of 50 investigations on bond strength," Quintessence International, vol. 28, no. 11, pp. 717723, 1997.

[9] Voco Research and development, Admira. A filling system based on ormocer. Technical Product Profile G14da. AntonFlemer-St. 1-3 D27472 Cuxhaven Germany 1999; 4-11.

[10] U. Blunck, F. Speyer, and J. F. Roulet, "Effect of hypochlorite treatment of conditioned dentin on the marginal adaptation of composite resin restorations," Journal of Dental Research, vol. 76, pp. 46-52, 1997.

[11] L. L. Ribeiro, S. A. Fatima Cristina de, and E. B. Franco, "Evaluation of the interaction between composite resin and different dentin adhesives," Revista de Odontologia da Universidade de Sao Paulo, vol. 13, no. 1, pp. 13-36, 1999.

[12] J. S. Earl, D. J. Wood, and S. J. Milne, "Dentine infiltration a cure for sensitive teeth," American Ceramic Society Bulletin, vol. 85, no. 7, pp. 22-25, 2006.

[13] J. S. Earl, D. J. Wood, and S. J. Milne, "Nanoparticles for dentine tubule infiltration: an in vitro study," Journal of Nanoscience and Nanotechnology, vol. 9, no. 11, pp. 6668-6674, 2009.

[14] J. S. Earl, R. K. Leary, J. S. Perrin et al., "Characterization of dentine structure in three dimensions using FIB-SEM," Journal of Microscopy, vol. 240, no. 1, pp. 1-5, 2010.

[15] T. Abo, S. Uno, and H. Sano, "Comparison of bonding efficacy of an all-in-one adhesive with a self-etching primer system," European Journal of Oral Sciences, vol. 112, no. 3, pp. 286-292, 2004.

[16] G. Hasshoff, H. M. Schneider, and K. Merte, "Toothcomposite interface from specific and nonspecific adhesive restorative systems," Journal of Biomedical Materials Research. Part B, vol. 71, no. 1, pp. 38-45, 2004.

[17] A. J. Gwinnett, "Moist versus dry dentin: its effect on shear bond strength," American Journal of Dentistry, vol. 5, no. 3, pp. 127-129, 1992. 

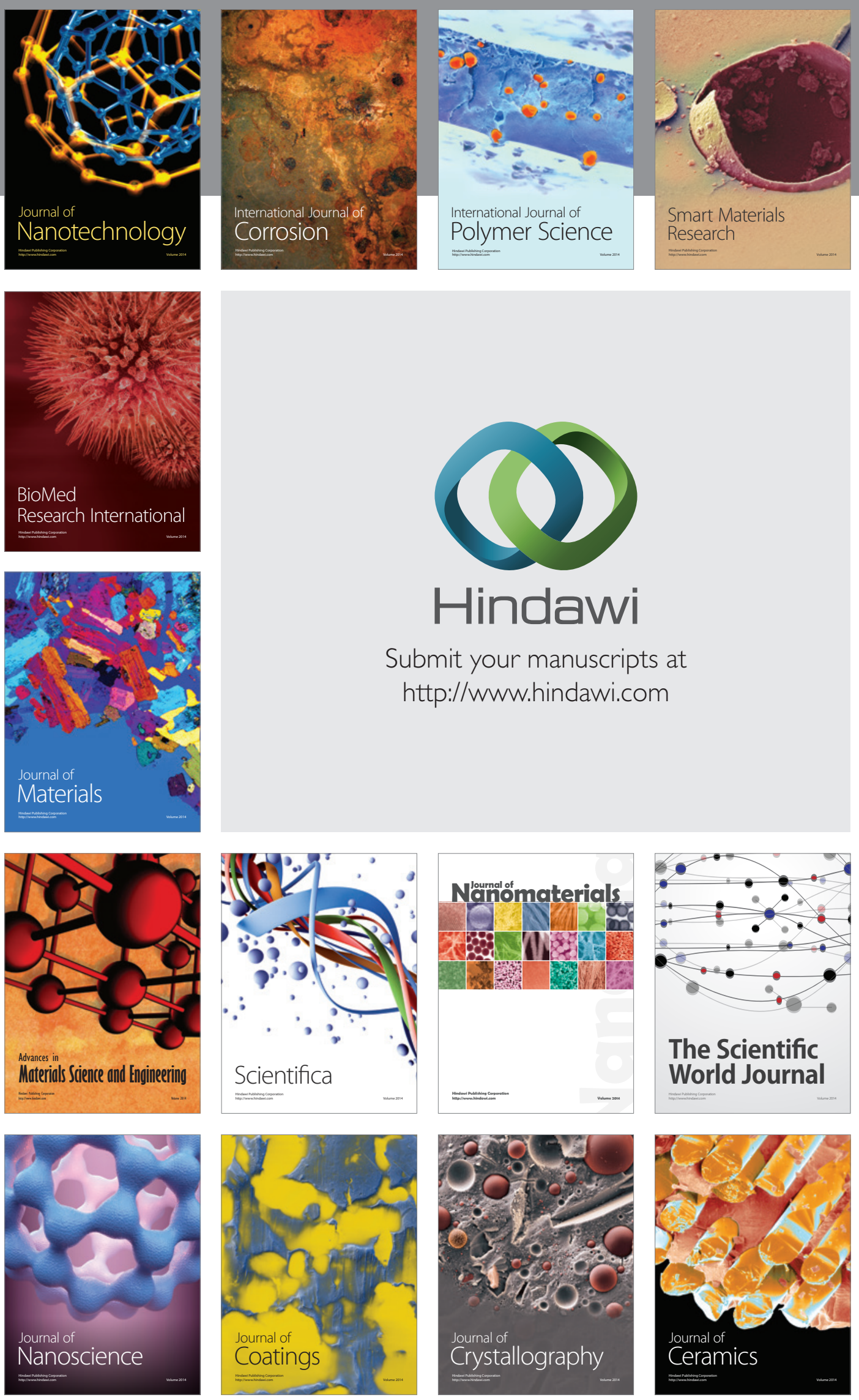

The Scientific World Journal

Submit your manuscripts at

http://www.hindawi.com

\section{World Journal}

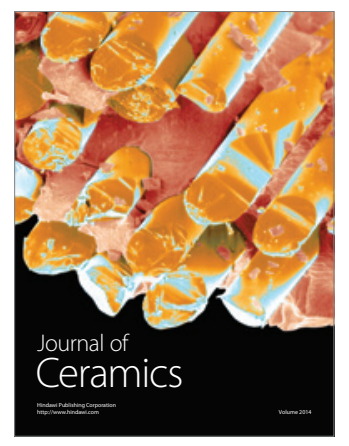

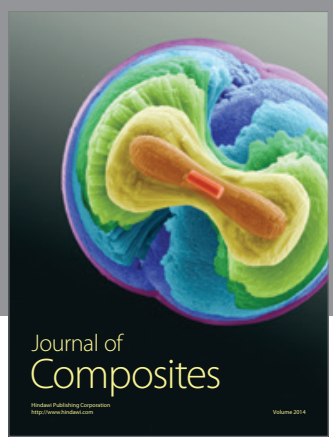
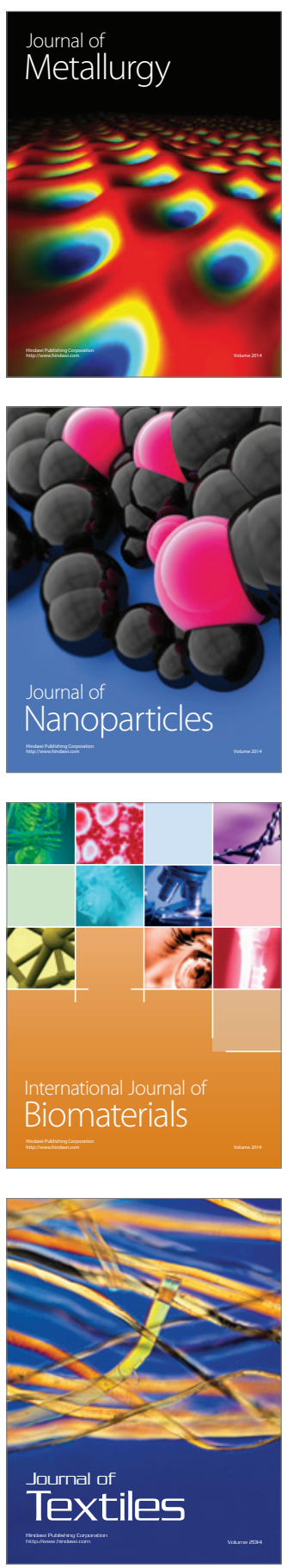